\title{
Evaluating the Performance of Ultrasound Screening for Congenital Heart Disease: A Descriptive Cohort Study
}

\author{
Rosemary J. Froehlich, MD ${ }^{1}$ Lindsay Maggio, MD, MPH ${ }^{1,2}$ Phinnara Has, MS 3 Erika F. Werner, MD, MS ${ }^{1}$ \\ Dwight J. Rouse, MD, MSPH${ }^{1}$
}

${ }^{1}$ Division of Maternal-Fetal Medicine, Department of Obstetrics and Gynecology, Women and Infants Hospital, Warren Alpert Medical School at Brown University, Providence, Rhode Island

2 Division of Maternal-Fetal Medicine, Department of Obstetrics and Gynecology, Maternal-Fetal Care Center, Florida Hospital Medical Group, Maitland, Florida

3 Division of Research, Department of Obstetrics and Gynecology, Women and Infants Hospital, Warren Alpert Medical School at Brown University, Providence, Rhode Island

Address for correspondence Rosemary J. Froehlich, MD, Department of Obstetrics and Gynecology, Women and Infants Hospital, Warren Alpert Medical School of Brown University, 101 Plain Street, 7th Floor, Providence, RI 02903 (e-mail: RFroehlich@wihri.org).

Am J Perinatol 2017;34:905-910.

\begin{abstract}
Keywords

- congenital heart disease

- CHD

- fetal anatomy ultrasound

- fetal echocardiography
\end{abstract}

Cardiac anomalies are the most common congenital malformation, with an estimated incidence of 4 to 13 per 1,000 live births. ${ }^{1-3}$ Consequently, congenital heart disease (CHD) is an important cause of neonatal morbidity and mortality. ${ }^{4-6}$

received

November 28, 2016

accepted after revision

February 15, 2017

published online

March 16, 2017
Advances in prenatal ultrasound have allowed for more frequent antenatal detection of $\mathrm{CHD}$, facilitating the care of affected infants at birth. ${ }^{7}$ Though the majority of these pregnancies occur in women without known risk factors,
Copyright $\odot 2017$ by Thieme Medical Publishers, Inc., 333 Seventh Avenue, New York, NY 10001, USA. Tel: +1(212) 584-4662.
DOI https://doi.org/ 10.1055/s-0037-1601309. ISSN 0735-1631. 
certain conditions, such as diabetes mellitus and family history of CHD, have been associated with increased risk of CHD. ${ }^{8-10}$ In pregnancies complicated by preexisting diabetes mellitus, rates of CHD have been reported to be as high as 21 to 46 per 1,000 live births. ${ }^{11}$ The recurrence rate for mothers who have previously given birth to an infant with CHD is $\sim 19$ per 1,000 live births. ${ }^{8}$

Recommendations by the American College of Obstetrics and Gynecology, the American Institute of Ultrasound in Medicine (AIUM), and the International Society of Ultrasound in Obstetrics and Gynecology are for women with known risk factors for CHD to undergo two screening tests, a detailed fetal anatomy ultrasound and a fetal echocardiogram, as opposed to anatomic survey alone. ${ }^{2,12-14}$ The utility of fetal echocardiography in diagnosing CHD after normal cardiac imaging on detailed anatomic survey has been questioned in previous work. ${ }^{6,11,15,16}$ Despite this, recommendations have not changed. Thus, we aimed to reassess the rate of abnormal fetal echocardiography after normal detailed anatomy ultrasound if interpreted by maternalfetal medicine specialists in a large, contemporary cohort of women meeting referral criteria for both exams.

\section{Materials and Methods}

After Institutional Review Board approval, we performed a retrospective review of women undergoing both detailed anatomy ultrasound and fetal echocardiography at the same regional prenatal diagnosis center between 2010 and 2014. Both anatomic survey and fetal echocardiography were performed between 16 and 26 weeks of gestation, and were interpreted by maternal-fetal medicine specialists. We chose this gestational age range to reflect routine referral patterns, while allowing some flexibility for those women presenting later to care. Women included had at least one indication for fetal echocardiography as recommended by the AIUM and normal cardiac anatomy on the initial detailed anatomic survey. We excluded women with previous abnormal ultrasound (e.g., thickened nuchal translucency, $\geq 3 \mathrm{~mm}$, or cystic hygroma), and those with abnormal or incomplete cardiac images on the initial anatomic survey. Echogenic intracardiac foci, choroid plexus cysts, and two-vessel umbilical cords were considered normal variants and were not excluded.

All detailed fetal anatomy ultrasounds were performed by Registered Diagnostic Medical Sonographers (RDMS) credentialed with an Obstetrics/Gynecology specialty at an AIUM accredited prenatal diagnosis center. Following RDMS certification, these sonographers were proctored by a senior board-certified maternal-fetal medicine specialist in the performance of the detailed anatomic survey. Exams were read and interpreted by maternal-fetal medicine specialists. During the study period, detailed anatomy ultrasounds assessed the four-chamber heart, and left and right ventricular outflow tract views only; additional views, such as the three-vessel trachea view, were not routinely performed. Fetal echocardiography was performed in real-time by select maternal-fetal medicine physicians according to published guidelines. $^{2}$
We collected maternal demographic information, body mass index (BMI), diabetic status, pregnancy characteristics including plurality, gestational age at the time of each ultrasound, as well as indications for and results of fetal echocardiography. When a cardiac abnormality was suspected prenatally, neonatal medical records were reviewed for any postnatal cardiac imaging results or special care (e.g., neonatal intensive care unit admission). Postnatal imaging to confirm normal fetal echocardiographic findings was not routinely performed. The primary outcome was abnormal fetal echocardiogram, defined as a structural cardiac abnormality. Cardiac abnormalities were considered major if likely to require surgery within the first 6 months of life, and minor if unlikely to require such intervention. Based on past work, we expected a detection rate of CHD by fetal echocardiogram after a normal anatomic survey of $3 \%$ or less. ${ }^{6,11,15,16}$ We chose an a priori sample size of 1,000 pregnancies to achieve a reasonably narrow $95 \%$ confidence interval $(\mathrm{CI})$ around an estimated primary outcome rate of 3\% (95\% CI: $2.0-4.3 \%$ ). Data analysis was performed with Stata/SE 13.1.

\section{Results}

We screened 1,883 ultrasound reports of women who underwent both detailed fetal anatomic survey and fetal echocardiography at our center between 2010 and 2014, of which we excluded 883 (-Fig. 1). After exclusions, the echocardiography results and medical records of 1,000 women carrying 1,052 fetuses were reviewed. The majority of women were Caucasian and multiparous ( - Table 1). There were 937 live births (including 45 twins and 1 set of triplets) at the hospital primarily affiliated with the prenatal diagnosis center, and 7 confirmed pregnancy losses or terminations. The majority of women had only one fetal echocardiogram during the studied pregnancy $(956 / 1,000)$, whereas 43 had two, and one woman had three, yielding a total of 1,045 fetal echocardiograms performed during the study period. The mean time between first detailed anatomic survey and fetal echocardiography was 10.3 days (standard deviation 12.1 days).

The most common indication for echocardiography was family history of CHD, followed by preexisting diabetes mellitus (-Table 2). There were 71 women referred for fetal echocardiography due to suspected preexisting diabetes mellitus, of which $67.6 \%$ had an abnormal diagnostic test for gestational diabetes at $\leq 13^{6 / 7}$ weeks' gestation. Of the nine women referred due to abnormal genetic testing (increased risk of aneuploidy or Smith-Lemli-Opitz syndrome by cell-free fetal deoxyribonucleic acid testing or integrated screening), seven underwent amniocentesis, identifying three abnormalities (trisomy 21, a balanced translocation involving chromosomes 2 and 16, and a 45, X/46, XY mosaic).

Of the 1,052 fetuses, 5 had an abnormal echocardiogram, 0.5\%, 95\% CI: $0.2-1.1 \%$ (-Table 3). Only one major cardiac anomaly was identified, which led to pregnancy termination (a complex defect involving a stenotic pulmonary valve and severe tricuspid regurgitation); neither invasive genetic testing nor fetal autopsy was performed. Four fetuses were 


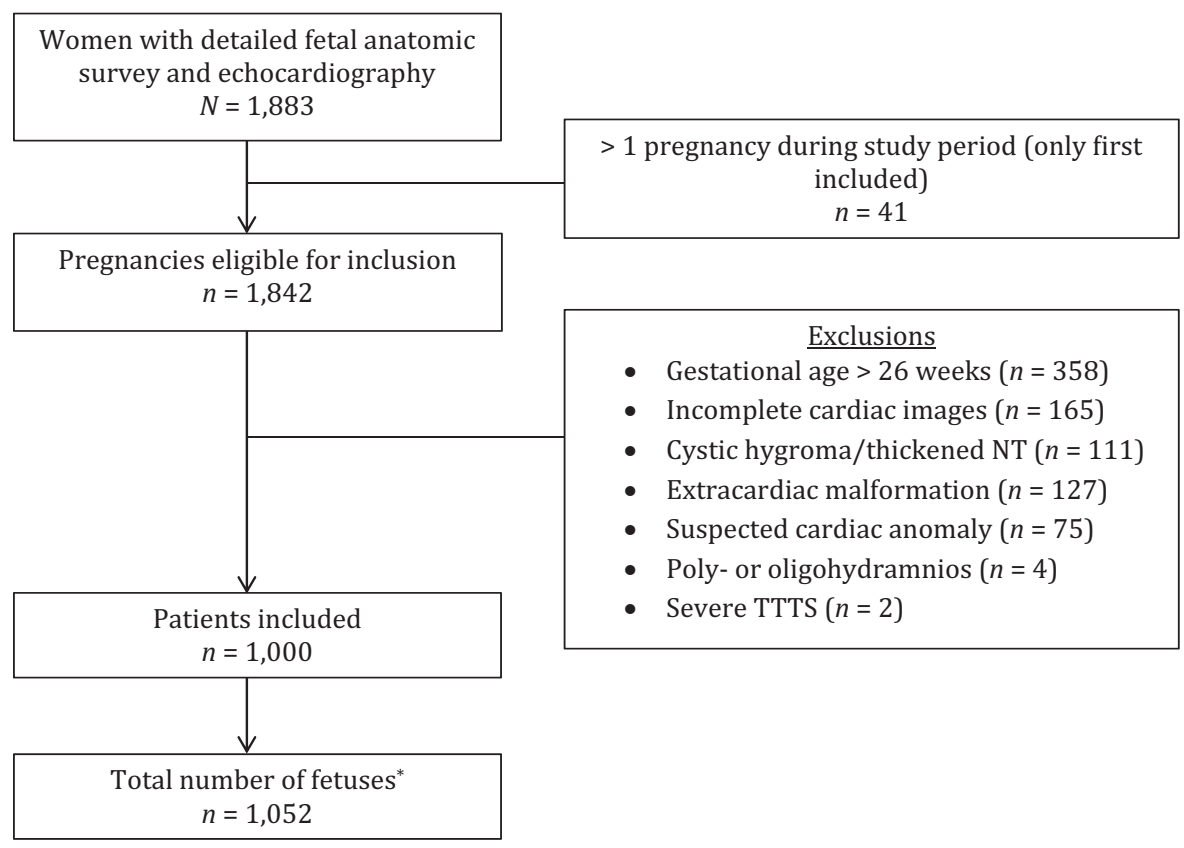

Fig. 1 Derivation of study population. NT, nuchal translucency; TTTS, twin-twin transfusion syndrome. "Twins $(n=50)$ and triplets $(n=1)$.

diagnosed with minor abnormalities (all ventricular septal defects), of which three had postnatal cardiac imaging that was normal. None of the four live-born infants with an abnormal fetal echocardiogram required special care in the immediate neonatal period.

\section{Discussion}

In this contemporary, well-characterized cohort of women meeting screening criteria for both detailed anatomy ultrasound and fetal echocardiography, the rate of abnormal fetal echocardiogram after a normal detailed anatomy ultrasound interpreted by maternal-fetal medicine specialists was low. The course of only 1 of 1,000 pregnancies $(0.1 \%)$ was altered on the basis of an abnormal echocardiogram following a normal detailed anatomy ultrasound. These findings suggest that when the detailed anatomy ultrasound is performed by a specialized physician, there may be limited utility to an additional fetal echocardiogram. We cannot comment on the utility of the fetal echocardiogram in other practice settings.

In background investigation, we conducted a search of the electronic databases Medline, PubMed, and the Cochrane Database of Systematic Reviews through November 2016 using the phrases or keywords "fetal echocardiography utility"; "fetal echocardiography" and (1) "normal anatomic survey," (2) "normal anatomy ultrasound," or (3) "level II ultrasound"; and "fetal echocardiography and CHD." We also reviewed the reference lists of each article identified in our electronic search for relevant studies. We were able to identify four studies that previously evaluated fetal echocardiography in women with normal cardiac imaging on anatomy ultrasound (results summarized along with our work in -Table 4). ${ }^{6,11,15,16}$ Though their methodologies were somewhat varied, all authors concluded that the utility of echocardiography in this setting is limited. Summing the data from these reports yields an abnormality rate of $0.1 \%$ (95\% CI: $0.03-0.29 \%$ ) for major or severe CHD, and 2.0\% (95\% CI: $1.5-2.5 \%)$ for minor or mild CHD by fetal echocardiography after normal cardiac imaging on anatomic survey. Our findings reinforce the conclusions made by these authors, and again raise important questions regarding the usefulness of fetal echocardiography as a second screening test after a normal detailed anatomy ultrasound.

The main strength of our study is its size; this is the largest evaluation of this question to date. We intentionally chose a sample size of 1,000 , whereas other studies were smaller and did not include a priori sample size calculations. Using strict inclusion and exclusion criteria, we studied a select cohort of women meeting screening criteria for fetal echocardiography, but who lacked first or second trimester ultrasonographic features that may have placed their fetuses at even higher risk of CHD. Thus, we were able to identify a specific group of women in whom detailed anatomic survey alone is likely a sufficient screening strategy for CHD. This is especially important in an era where medical care dollars are becoming increasingly constrained. Pinto et al estimated the cost of one fetal echocardiogram to be $\$ 358$ (2015 USD). ${ }^{17}$ In our cohort, 1,045 fetal echocardiograms were performed to identify one clinically significant abnormality. Using their cost estimate means we expended $\$ 374,110$ to identify one clinically significant fetal cardiac abnormality.

It is important to note that the purpose of this study was not to define the performance (i.e., sensitivity and specificity) of fetal echocardiography as a screening test, which would have required postnatal echocardiography of all neonates included in the study. Rather, our aim was to determine 
Table 1 Baseline characteristics of women undergoing fetal echocardiography

\begin{tabular}{|c|c|}
\hline Variable & $N=1,000$ women \\
\hline Maternal age (y) & $30.0(26.0-34.0)$ \\
\hline Nulliparous & $364(36.4)$ \\
\hline Twins & $50(5.0)$ \\
\hline Monochorionic/monoamniotic & $0(0)$ \\
\hline Monochorionic /diamniotic & $26(2.6)$ \\
\hline Dichorionic/diamniotic & $24(2.4)$ \\
\hline Triplets & $1(0.10)$ \\
\hline \multicolumn{2}{|l|}{ Ethnicity/race } \\
\hline White & $665(66.5)$ \\
\hline African American & $73(7.3)$ \\
\hline Hispanic & $161(16.1)$ \\
\hline Asian & $42(4.2)$ \\
\hline Other & $59(5.9)$ \\
\hline BMI $\left(\mathrm{kg} / \mathrm{m}^{2}\right)$ at first prenatal visit & $\begin{array}{l}n=641 \\
26.7(23.4-32.2)\end{array}$ \\
\hline Diabetes & $n=924$ \\
\hline Type 1 & $65(7.0)$ \\
\hline Type 2 & $137(14.8)$ \\
\hline Gestational & $137(14.8)$ \\
\hline \multicolumn{2}{|l|}{ First trimester Hgb A1c (\%) } \\
\hline Type 1 & $\begin{array}{l}n=55 \\
7.5(7.0-8.3)\end{array}$ \\
\hline Type 2 & $\begin{array}{l}n=96 \\
6.7(6.1-8.1)\end{array}$ \\
\hline IVF & $50(5.0)$ \\
\hline $\begin{array}{l}\text { Gestational age at first } \\
\text { anatomy US (wk) }\end{array}$ & $20.0(18.6-21.1)$ \\
\hline $\begin{array}{l}\text { Gestational age at first } \\
\text { fetal echo (wk) }\end{array}$ & $21.1(20.6-22.1)$ \\
\hline
\end{tabular}

Abbreviations: BMI, body mass index; IVF, in vitro fertilization; US, ultrasound.

Note: Data presented as $n$ (\%) or median (interquartile range).

how often echocardiography will be deemed abnormal after a normal detailed anatomy ultrasound, and the subsequent effect the results may have on prenatal management or immediate neonatal care. We must also note that in the years following the study period, the cardiac views routinely included in the detailed anatomy ultrasound at our center have been expanded in accordance with updated guidelines. ${ }^{18}$ In addition to the four-chamber heart, and left and right ventricular outflow tract views, we now routinely assess the aortic arch, three-vessel and three-vessel trachea, and superior and inferior vena cavae views. Repeating this study in light of these expanded views would likely yield an even lower rate of abnormal echocardiogram after a normal detailed anatomy ultrasound.
Table 2 Indications for fetal echocardiography

\begin{tabular}{|l|l|}
\hline Indication & $N=1,000$ women \\
\hline Family history of CHD & $426(42.6)$ \\
\hline \multicolumn{1}{|c|}{ First degree relative } & $268(62.9)$ \\
\hline \multicolumn{1}{|c|}{ Other or unspecified } & $158(37.1)$ \\
\hline Preexisting diabetes mellitus $^{\text {a }}$ & $190(19)$ \\
\hline Other $^{\text {a }}$ & $118(11.8)$ \\
\hline Drug exposure & $95(9.5)$ \\
\hline Fetal arrhythmia & $65(6.5)$ \\
\hline Multiple indications & $50(5.0)$ \\
\hline Monochorionic twins & $23(2.3)$ \\
\hline Assisted reproductive technology & $19(1.9)$ \\
\hline+ SSA or + SSB antibodies & $7(0.7)$ \\
\hline Inherited disorder & $7(0.7)$ \\
\hline
\end{tabular}

Abbreviation: CHD, congenital heart disease.

Note: Data presented as $n(\%)$.

${ }^{a}$ Suspected preexisting diabetes mellitus $(n=71)$, abnormal genetic testing ( $n=9)$, two-vessel umbilical cord $(n=15)$, and others.

We acknowledge several study limitations. This study was performed in a population in which all detailed anatomy ultrasounds and fetal echocardiograms are interpreted by maternal-fetal medicine specialists. Our findings may not be reproducible in settings with other screening practices, especially when performed by physicians other than maternal-fetal medicine specialists, or those with lower CHD prenatal detection rates. In addition, as a referral center, some women present for ultrasonography but deliver elsewhere. Consequently, we did not have access to complete prenatal records or outcome data for all women included in the study. This led to some missing maternal demographic data, such as BMI, and may also have limited our ability to assign the true indication(s) for fetal echocardiography. Similar to Starikov et al, we excluded women with incomplete cardiac views at the time of the anatomy ultrasound. Consequently, this analysis cannot be used to comment on the most appropriate next screening step for these women. Finally, we did not correct for correlation among the minority of women who had more than one fetal echocardiogram. However, doing so, given the infrequency of detected cardiac abnormalities, could not have materially affected our conclusions.

Fetal echocardiography is routinely performed for women at increased risk of CHD in addition to detailed anatomic survey without clear evidence of benefit. In a high-resource setting, where all exams are interpreted by maternal-fetal medicine specialists, the addition of fetal echocardiography after a normal detailed anatomy ultrasound is unlikely to change clinical management or to be cost-effective. As we strive to maximize health care efficiency and minimize costs, it may be most effective to encourage detailed anatomy ultrasounds performed by specialists, reducing the need for additional imaging in some patients. 
Evaluating the Performance of Ultrasound Screening for CHD Froehlich et al. 909

Table 3 Distribution of abnormal fetal echocardiograms and outcomes

\begin{tabular}{|l|l|l|l|l|}
\hline Participant & $\begin{array}{l}\text { Suspected } \\
\text { cardiac anomaly }\end{array}$ & $\begin{array}{l}\text { Indication for fetal } \\
\text { echocardiogram }\end{array}$ & $\begin{array}{l}\text { Pregnancy } \\
\text { outcome }\end{array}$ & $\begin{array}{l}\text { Postnatal imaging } \\
\text { or autopsy result }\end{array}$ \\
\hline 1 & VSD & Family history of CHD & Live birth & Normal \\
\hline 2 & VSD & Family history of CHD & Live birth & Normal \\
\hline 3 & VSD & ART & Live birth & None available \\
\hline 4 & VSD & Trisomy 21 on amniocentesis & Live birth & Normal \\
\hline 5 & $\begin{array}{l}\text { Complex structural } \\
\text { heart defect }\end{array}$ & Family history of CHD & Termination & None available \\
\hline
\end{tabular}

Abbreviations: ART, artificial reproductive technology; CHD, congenital heart disease; VSD, ventricular septal defect.

anvolved a stenotic pulmonary valve and severe tricuspid regurgitation.

Table 4 Summary of the current and prior studies

\begin{tabular}{|c|c|c|c|c|c|}
\hline Study & Inclusions & $\begin{array}{l}\text { Cardiac images } \\
\text { in anatomy US }\end{array}$ & $\begin{array}{l}\text { Most common } \\
\text { indications } \\
\text { for fetal echo }\end{array}$ & $\begin{array}{l}\text { Major }^{\mathrm{a}} \text { or } \\
\text { severe }^{\mathrm{b}} \mathrm{CHD}\end{array}$ & $\begin{array}{l}\text { Minor }{ }^{\mathrm{c}} \text { or } \\
\text { mild }^{\mathrm{d}} \text { CHD }\end{array}$ \\
\hline $\begin{array}{l}\text { Muller } \\
\text { et al } \\
(2005)\end{array}$ & $\begin{array}{l}\text { Anatomy US and fetal echo } \\
\text { at same facility } \\
\text { Fetal echo at } 17-30 \mathrm{wk}\end{array}$ & $\begin{array}{l}4 \mathrm{CH} \\
\text { LVOT }\end{array}$ & $\begin{array}{l}\text { Preexisting DM } \\
\text { Fetal anomaly } \\
\text { Family history of CHD }\end{array}$ & $2 / 578(0.4 \%)$ & $4 / 578^{e}(0.7 \%)$ \\
\hline $\begin{array}{l}\text { Starikov } \\
\text { et al } \\
(2009)\end{array}$ & $\begin{array}{l}\text { Anatomy US at } 16-20 \mathrm{wk} \\
\text { with normal cardiac images } \\
\text { Fetal echo at same facility }\end{array}$ & $\begin{array}{l}\text { 4CH } \\
\text { LVOT } \\
\text { RVOT }\end{array}$ & $\begin{array}{l}\text { AMA } \\
\text { US marker of aneuploidy } \\
\text { Family history of CHD }\end{array}$ & $0 / 481(0.0 \%)$ & $1 / 481^{f}(0.2 \%)$ \\
\hline $\begin{array}{l}\text { Sekhavat } \\
\text { et al }{ }^{15} \\
(2010)\end{array}$ & $\begin{array}{l}\text { Anatomy US and fetal echo } \\
\text { at same facility } \\
\text { Maternal DM } \\
\text { Excluded suspected CHD } \\
\text { and GA > } 29 \text { wk }\end{array}$ & Not specified & Maternal DM & $0 / 584(0.0 \%)$ & $19 / 584(3.3 \%)$ \\
\hline $\begin{array}{l}\text { Friedman } \\
\text { et al } \\
(2011)^{g}\end{array}$ & $\begin{array}{l}\text { Anatomy US and fetal echo } \\
\text { at same facility } \\
\text { Normal anatomy US }\end{array}$ & $\begin{array}{l}4 \mathrm{CH} \\
\text { LVOT } \\
\text { RVOT } \\
\text { Aortic arch } \\
\text { Ductal arch }\end{array}$ & $\begin{array}{l}\text { Family history of CHD } \\
\text { DM }\end{array}$ & $0 / 371(0.0 \%)$ & $31 / 371(9.8 \%)$ \\
\hline $\begin{array}{l}\text { Froehlich } \\
\text { et al } \\
(2016)^{g}\end{array}$ & $\begin{array}{l}\text { Anatomy US and fetal echo at } \\
\text { same facility at } 16-26 \mathrm{wk} \\
\text { Normal anatomy US }\end{array}$ & $\begin{array}{l}4 \mathrm{CH} \\
\text { LVOT } \\
\text { RVOT }\end{array}$ & $\begin{array}{l}\text { Preexisting DM } \\
\text { Family history of CHD }\end{array}$ & $1 / 1,000(0.1 \%)$ & $4 / 1,000(0.4 \%)$ \\
\hline \multicolumn{4}{|c|}{ Total (\%) (95\% Cl) } & $\begin{array}{l}3 / 3,014(0.1) \\
(0.03-0.29)\end{array}$ & $\begin{array}{l}59 / 3,014(2.0) \\
(1.5-2.5)\end{array}$ \\
\hline
\end{tabular}

Abbreviations: $4 \mathrm{CH}$, four-chamber heart; $\mathrm{AMA}$, advanced maternal age; $\mathrm{CHD}$, congenital heart disease; $\mathrm{Cl}$, confidence interval; DM, diabetes mellitus; GA, gestational age; LVOT, left ventricular outflow tract; RVOT, right ventricular outflow tract; US, ultrasound.

${ }^{a}$ Major CHD requires medical or surgical intervention within first 6 months or year of life.

${ }^{b}$ Severe CHD requires surgical intervention or mandatory cardiac follow-up.

${ }^{c}$ Minor CHD unlikely to require surgery within first 6 months of life.

${ }^{\mathrm{d}}$ Mild CHD not likely to be hemodynamically significant but might require postnatal follow-up.

eNumber of women with normal cardiac images on anatomy ultrasound.

fVentricular septal defect categorized as "minor" for purposes of this table.

${ }^{9}$ Excludes fetuses with extracardiac malformations.

\section{References}

1 van der Linde D, Konings EE, Slager MA, et al. Birth prevalence of congenital heart disease worldwide: a systematic review and meta-analysis. J Am Coll Cardiol 2011;58(21):2241-2247

2 American Institute of Ultrasound in Medicine. AIUM practice guideline for the performance of fetal echocardiography. J Ultrasound Med 2013;32(6):1067-1082

3 Liu H, Zhou J, Feng QL, et al. Fetal echocardiography for congenital heart disease diagnosis: a meta-analysis, power analysis and missing data analysis. Eur J Prev Cardiol 2015;22(12):1531-1547
4 Rosano A, Botto LD, Botting B, Mastroiacovo P. Infant mortality and congenital anomalies from 1950 to 1994: an international perspective. J Epidemiol Community Health 2000;54(9): 660-666

5 Killen SA, Mouledoux JH, Kavanaugh-McHugh A. Pediatric prenatal diagnosis of congenital heart disease. Curr Opin Pediatr 2014; 26(5):536-545

6 Friedman AM, Phoon CK, Fishman S, Seubert DE, Timor-Tritsch IE, Schwartz N. The utility of fetal echocardiography after an unremarkable anatomy scan. Obstet Gynecol 2011;118(4):921-927 
910 Evaluating the Performance of Ultrasound Screening for CHD Froehlich et al.

7 Rychik J, Ayres N, Cuneo B, et al. American Society of Echocardiography guidelines and standards for performance of the fetal echocardiogram. J Am Soc Echocardiogr 2004;17(7):803-810

8 Allan LD, Crawford DC, Chita SK, Anderson RH, Tynan MJ. Familial recurrence of congenital heart disease in a prospective series of mothers referred for fetal echocardiography. Am J Cardiol 1986; 58(3):334-337

9 Starikov R, Bohrer J, Goh W, et al. Hemoglobin A1c in pregestational diabetic gravidas and the risk of congenital heart disease in the fetus. Pediatr Cardiol 2013;34(7):1716-1722

10 Perri T, Cohen-Sacher B, Hod M, Berant M, Meizner I, Bar J. Risk factors for cardiac malformations detected by fetal echocardiography in a tertiary center. J Matern Fetal Neonatal Med 2005; 17(2):123-128

11 Starikov RS, Bsat FA, Knee AB, Tsirka AE, Paris Y, Markenson GR. Utility of fetal echocardiography after normal cardiac imaging findings on detailed fetal anatomic ultrasonography. J Ultrasound Med 2009;28(5):603-608

12 American Institute of Ultrasound in Medicine. AIUM practice guideline for the performance of obstetric ultrasound examinations. J Ultrasound Med 2013;32(6):1083-1101
13 Carvalho JS, Allan LD, Chaoui R, et al; International Society of Ultrasound in Obstetrics and Gynecology. ISUOG Practice Guidelines (updated): sonographic screening examination of the fetal heart. Ultrasound Obstet Gynecol 2013;41(3):348-359

14 American College of Obstetricians and Gynecologists. ACOG Practice Bulletin No. 101: Ultrasonography in pregnancy. Obstet Gynecol 2009;113(2 Pt 1):451-461

15 Sekhavat S, Kishore N, Levine JC. Screening fetal echocardiography in diabetic mothers with normal findings on detailed anatomic survey. Ultrasound Obstet Gynecol 2010;35(2): 178-182

16 Muller PR, James A, Feldman K, Herlong JR. Utility of fetal echocardiogram in high-risk patients. Aust N Z J Obstet Gynaecol 2005;45(2):117-121

17 Pinto NM, Nelson R, Puchalski M, Metz TD, Smith KJ. Costeffectiveness of prenatal screening strategies for congenital heart disease. Ultrasound Obstet Gynecol 2014;44(1):50-57

18 Wax J, Minkoff $\mathrm{H}$, Johnson A, et al. Consensus report on the detailed fetal anatomic ultrasound examination: indications, components, and qualifications. J Ultrasound Med 2014;33(2): 189-195 